\title{
Depreciação no setor público: o déficit da produção científica
}

\author{
Gleice Carvalho de Lima Moreno \\ Universidade Federal de Rondônia \\ Brasil \\ Bacharel em Ciências Contábeis pela Universidade Estadual da Paraíba (UEPB) e Mestre em \\ Controladoria pela Universidade Federal de Pernambuco (UFPE).
}

\section{Luiz Carlos Miranda}

Universidade Federal de Pernambuco

Brasil

Ph.D. no Program In Agribusiness, pela University of Illinois

José Moreira da Silva Neto

Universidade Federal de Rondônia

Brasil

Doutor em Engenharia da Produção, pela Universidade Federal de Santa Catarina

Artigo submetido em: 04/11/2016

Aprovado em: 06/09/2017

\begin{abstract}
RESUMO
Investigamos como ocorreu a progressão da pesquisa científica sobre depreciação no ambiente público, impulsionada pela harmonização das Normas Brasileiras de Contabilidade Aplicadas ao Setor Público aos padrões internacionais. A metodologia tomou por base a análise bibliométrica, possibilitando definir o universo da pesquisa formado por 27 revistas e dois eventos da área contábil. O período de análise considerou as publicações de 2011 a 2015. Os artigos selecionados para análise foram aqueles que tinham a expressão "depreciação" no título ou resumo, havendo a rejeição para os artigos associados ao ambiente privado. $\mathrm{O}$ resultado detectou que a progressão da pesquisa científica foi muito baixa, por causa da reduzida contribuição dos pesquisadores para a temática abordada neste estudo.
\end{abstract}

Palavras-chave: Depreciação. Ambiente público. Análise bibliométrica.

\section{Depreciation in the Public Sector: The Deficit Scientific Production}

\begin{abstract}
We investigated how the progression of scientific research on depreciation in the public environment occurred, driven by the harmonization of the Brazilian Accounting Standards Applied to the Public Sector to international standards. The methodology was based on bibliometric analysis, making it possible to define the universe of the research formed by 27 journals and two events in the accounting area. The period of analysis considered the
\end{abstract}


publications from 2011 to 2015 . The articles selected for analysis were those that had the expression "depreciation" in the title or abstract, rejecting articles associated with the private environment. The result found that the progression of scientific research was very low, due to the reduced contribution of the researchers to the topic addressed in this study.

Keywords: Depreciation. Public Environment. Bibliometric Analysis.

\section{Introdução}

Com o processo de harmonização das Normas Brasileiras às Normas Internacionais de Contabilidade, ocorreram mudanças no ambiente privado e público. Essas mudanças passaram a ser consideradas com o propósito de possibilitar a compreensão das informações divulgadas nos demonstrativos contábeis, evitando interpretações confusas. Dentre as alterações estabelecidas com a harmonização das normas contábeis no ambiente público, passou a ser obrigado o reconhecimento da depreciação sobre o imobilizado da administração pública, causando impactos significativos em relação ao imobilizado, aos custos e aos resultados (HARZER e SOUZA, 2014).

De acordo com Graciliano e Fialho (2013) o registro da depreciação, que representa o desgaste físico dos bens, tornou-se procedimento preponderante por determinar a eficiência dos recursos aplicados no âmbito público, permitindo um maior controle social sobre as contas do Estado. Os mesmos autores afirmam ainda que os relatórios contábeis da gestão pública a partir dessa compulsoriedade têm contribuído para o disclosure contábil, um dos fatores da governança corporativa, tão importante para uma boa gestão pública. Complementando esse estudo Roza, Machado e Quintana (2011) elaboraram por meio de análise bibliométrica da produção científica sobre contabilidade pública uma pesquisa, onde foi percebido que o tema predominante nos artigos é o controle e a transparência das contas públicas, ficando clara a necessidade da aplicação de pelo menos esses dois fatores nas três esferas da federação.

A adoção da depreciação no ambiente público, foi vista por Miranda, Lima e Ferreira (2010) como fator de extrema necessidade, pois as informações evidenciavam valores que não refletiam a realidade econômica das entidades. Em pesquisa realizada junto ao Tribunal Regional do Trabalho da $10^{\mathrm{a}}$ Região, esses pesquisadores constataram que para aplicação desse procedimento foi preciso restabelecer o valor original dos bens do imobilizado, por intermédio da reavaliação e de impairment, procedimentos já compreendidos nas Normas Brasileiras de Contabilidade Aplicadas ao Setor Público.

Considerando a implementação dessa nova sistemática para o ambiente público, investigamos como ocorreu a progressão da pesquisa científica sobre depreciação no âmbito 
governamental, impulsionada pela harmonização das Normas Brasileiras Aplicadas ao Setor Público às normas internacionais de contabilidade, observando a conduta das pesquisas científicas para a propagação dessa nova sistemática no meio acadêmico e profissional. Neste contexto, esta pesquisa busca por meio de análise da produção científica responder a seguinte questão: Qual o nível de progressão da produção científica sobre a depreciação no ambiente público após o processo de harmonização das normas contábeis?

Dessa forma, observamos a importância desta pesquisa por analisar estudos desenvolvidos por outros pesquisadores, refletindo no registro da depreciação e a consequente adaptação dos órgãos a esse novo procedimento, que melhora o controle e a transparência do patrimônio na esfera pública.

\section{Depreciação no ambiente público}

O patrimônio público, representado por bens móveis e imóveis, pertencentes ao Estado, assim como o patrimônio de entidades privadas, sofrem a deterioração no decorrer dos anos para a devida prestação dos serviços. Com isso os danos causados pelo uso constante, devem ser reconhecidos na contabilidade, para determinar os custos ou despesas e favorecer a gestão na tomada de decisões (SILVA et al, 2011).

O controle, para fins de depreciação e em muitos outros casos, é fundamental para a construção da informação segura, proveniente da contabilidade. Dessa forma, as entidades precisam de documentos que comprovem os aspectos físico, material, financeiro, espacial e temporal, destacando o período de entrada dos bens, o valor de aquisição, o local da compra, as características físicas do bem e a base de cálculo para os tributos, permitindo assim, que todas as informações necessárias para o seu registro sejam consideradas. Os valores dos bens devem ser atualizados, por intermédio da depreciação com ajustes realizados pela contabilidade, por meio da redução ao valor recuperável (teste de impairment), pela determinação da vida útil e do valor residual, utilizando alguns procedimentos em sintonia com as orientações do Manual de Contabilidade Aplicado ao Setor Público, (VIANA et al, 2013).

O Código Civil Brasileiro em seu Art. 98 deixa claro que são públicos os bens de domínio nacional pertencentes às pessoas jurídicas de direito público interno e em seu Art. 99 descreve quais são os bens públicos:

I - Os de uso comum do povo, tais como rios, mares, estradas, ruas e praças; 
II - Os de uso especial, tais como edifícios ou terrenos destinados a serviço ou estabelecimento da administração federal, estadual, territorial ou municipal, inclusive os de suas autarquias.

III - Os dominicais, que constituem o patrimônio das pessoas jurídicas de direito público, como objeto de direito pessoal, ou real, de cada uma dessas entidades.

Contudo, os bens descritos no inciso I do Código Civil, àqueles que são considerados de uso comum do povo, são livres de registros contábeis pois não formam o patrimônio de um órgão público. Logo, não podem ser considerados na contabilidade pública. Quanto aos demais bens que atendam de acordo com Tesouro Nacional (2007), "à característica de uso restrito, específico e não generalizado de propriedade das entidades públicas" são considerados patrimônio público devendo ser contabilizados de forma a reconhecer a depreciação.

Diante da infinidade de bens dispostos nos órgãos públicos, esperamos que seja possível a inserção desse procedimento oriundo do processo de harmonização das normas contábeis aplicadas à área pública, tornando possível responder a essa nova demanda de informação.

\section{Impactos da depreciação no setor público}

Uma das referências abordada neste estudo, apresentou após análise em vinte dos estados da federação e Distrito Federal que a depreciação foi realizada apenas pelos Estados da Paraíba, Bahia, Acre, Pernambuco, Pará, Rio de Janeiro, Santa Catarina e Minas Gerais, apontando o impacto da depreciação, como sendo insignificante do ponto de vista patrimonial e de resultado (BORGHETTI, et al, 2012). Complementando a pesquisa anterior Silva et al. (2014) destacaram que os índices econômicos e financeiros de uma entidade estudada sofreram alteração de valor, mas isso não comprometeu o patrimônio da entidade. Ressaltaram ainda que o impacto maior ocorreu no período de aplicação dessa nova sistemática, com a expectativa de normalização em períodos consecutivos.

Hazer e Souza (2014) desenvolveram um estudo de caso junto a uma companhia pública municipal de abastecimento de água e constataram um impacto médio no imobilizado de $26,5 \%$ e nos resultados de $32,5 \%$ sobre o superávit corrente. Contudo, confirmaram que o impacto no patrimônio e resultado é estável. Dessa forma, a depreciação deve ser reconhecida pelas entidades públicas, para apresentação de informações contábeis verídicas, estando em conformidade com a legislação pertinente.

O registro dos valores de depreciação do ativo imobilizado de acordo com Carvalho, Lima e Ferreira (2012) são indispensáveis para o processo de reconhecimento e mensuração de 
tal ativo. Entretanto, no estudo de caso realizado constataram que a empresa estudada, adotava procedimento contábil de depreciação para os bens adquiridos a partir de 2010, mas ainda não executavam os procedimentos relativos à reavaliação e ajuste de impairment para os bens adquiridos em período anterior.

Com a implantação da depreciação no ambiente público Tedros et al. ( 2015) acreditam que será possível dar dimensões em relação ao impacto sobre as receitas e sobre o orçamento para as novas aquisições, reposições e manutenções do patrimônio que é utilizado nos serviços públicos, além de permitir a análise da eficiência e eficácia do imobilizado.

Sendo assim, acreditamos que o impacto gerado foi temporário. À medida que, esse novo procedimento se tornar hábito nos órgãos públicos, será possível mensurar os reais custos gerados na prestação dos serviços públicos e a evolução patrimonial de cada órgão.

\section{Métodos de depreciação - Novas propostas}

Apresentamos nesta seção os métodos de depreciação mais usados no Brasil e, também, os métodos apontados pela Norma Brasileira de Contabilidade $\mathrm{n}^{\circ}$ 16.9, Resolução 1.136/08, empregada no setor público. O primeiro deles se refere ao Método de Quotas Constantes, cuja característica é o uso de uma taxa constante, como o próprio nome indica. O segundo é o da Soma dos Dígitos, contrário ao primeiro a taxa é variável. O terceiro é o das Unidades Produzidas calculado com base na produção esperada.

O Manual de Contabilidade Aplicado ao Setor Público (MCASP) considerado mais um instrumento de orientação para a profissão contábil, em sua Parte II informa sobre a não exigência do mesmo modelo para todos os elementos do imobilizado, utilizando o modelo que mais se adequar às características do bem. Ressaltando que alguns bens públicos não sofrem depreciação, como os terrenos e os bens de natureza cultural. O segundo caso por serem geralmente insubstituíveis e por não se conseguir estimar a vida útil.

O método das Quotas Constantes de acordo com Graciliano e Fialho (2013) é o procedimento mais utilizado pela simplicidade, pela exigência fiscal e por tornar a eficiência do bem constante ao longo de sua vida útil.

Tomando por base os procedimentos já adotados, criamos uma nova maneira de calcular o valor líquido do bem após o i-ésimo ano de depreciação: 


$$
V_{i}=V_{0}-\frac{\left(V_{0}-V_{R}\right)}{n} i
$$

Onde o $V_{i}$ representa o valor líquido do bem após o i-ésimo ano de sua vida útil, o $V_{0}$ é o valor de aquisição do bem, o $V_{R}$ é o valor residual caso seja considerado, o $n$ refere-se à vida útil do bem e o $i$ é o i-ésimo ano da depreciação.

O método da Soma dos Dígitos segundo Bezerra Filho (2014) é representado por uma taxa decrescente de depreciação, tendo maiores quotas no início da vida útil do bem e menores quotas ao final, acompanhando o desgaste dos bens que em sua maioria são registrados no imobilizado, sendo mais comum, de acordo com o autor, o reconhecimento desse método em veículos.

Partindo do Método da Soma dos Dígitos, elaboramos após algumas manipulações algébricas a equação a seguir, como nova proposta para o cálculo da depreciação, apresentando como resultado o valor líquido do bem após o i-ésimo ano de depreciação:

$$
V_{i}=V_{0}-\left(\frac{2(n+1) i-i(i+1)}{n(n+1)}\right) V_{0}-V_{R}
$$

O método das Unidades Produzidas conforme Bezerra Filho (2014) determina a vida útil do bem de acordo com a sua capacidade produtiva. Neste sentido, observando o que já se tem e após algumas tentativas, produzimos a equação abaixo, com o propósito de avaliar o valor líquido do bem após o i-ésimo ano de depreciação:

$$
V_{i}=V_{0}-\left(V_{0}-V_{R}\right)\left(\frac{C_{P A}}{C_{P T}}\right) i,
$$

sendo $C_{P A}$ a capacidade produtiva anual e $C_{P T}$ a capacidade produtiva total do bem.

Nesta seção, formamos expressões analíticas fechadas como uma única equação para cada método, identificando o valor do bem após um período de tempo de depreciação no decorrer de sua vida útil.

\section{Abordagem metodológica}

A pesquisa, então desenvolvida, foi construída fazendo uso da análise bibliométrica que busca descrever as características e as propriedades de um determinado assunto, fazendo uso 

produção científica. Revista Unemat de Contabilidade, v. 6, n. 12, 2017.

dos aspectos pré-textuais, textuais e pós-textuais de produção científica (CAFÉ e BRÄSCHER, 2008). A bibliometria é uma ferramenta que mede os aspectos selecionados utilizando técnicas estatísticas, para a realização de comparações dos elementos bibliográficos (HAYASHI, 2012). A análise bibliométrica foi utilizada, neste caso, com o propósito de investigar a progressão tanto quantitativa quanto qualitativa da pesquisa científica sobre a depreciação no ambiente público. Logo, a abordagem desta pesquisa se caracteriza como quantitativa, por organizar os dados coletados pela tabulação e cruzamento de dados (DALFOVO, LANA e SILVEIRA, 2008).

A amostra explorada neste estudo foi intencional, pois fizemos a seleção das revistas pelo Qualis Capes, além de incluir revistas de três universidades federais e uma privada ainda não qualificadas. Quanto aos eventos usamos os dados disponíveis na internet. Definida a amostra partimos para a população, representada por artigos científicos, existente nos anais de eventos e em revistas científicas do período de 2011 até 2015. Os artigos selecionados foram aqueles cujos temas tivessem relação com o setor público, especificamente o de depreciação. Dessa forma, a amostra foi selecionada utilizando como universo da pesquisa as revistas e eventos destacados no Quadro 1.

Quadro 1. Universo e Amostra da Pesquisa.

\begin{tabular}{|r|l|l|c|c|}
\hline \multicolumn{1}{|c|}{$\mathbf{N}^{\mathbf{0}}$} & \multicolumn{1}{|c|}{ Revistas e Eventos } & \multicolumn{1}{c|}{ IES } & Classificação & $\begin{array}{c}\text { Artigos } \\
\text { analisados }\end{array}$ \\
\hline 1 & Contabilidade Vista e Revista & UFMG & - & 0 \\
\hline 2 & Brasileira de Gestão de Negócios & FECAP & A2 & 0 \\
\hline 3 & BASE & UNISINOS & B2 & 0 \\
\hline 4 & Revista Ambiente Contábil & UFRN & B3 & 0 \\
\hline 5 & Con Texto & UFRGS & B3 & 0 \\
\hline 6 & Pensar Contábil & CRC/RJ & B4 & 1 \\
\hline 7 & $\begin{array}{l}\text { Administração, Contabilidade e } \\
\text { Economia }\end{array}$ & UNOESC & B3 & 0 \\
\hline 8 & da Associação Brasileira de Custos & ABCustos & B4 & 0 \\
\hline 9 & $\begin{array}{l}\text { Administração, Contabilidade e } \\
\text { Sustentabilidade }\end{array}$ & UFCG & - & 0 \\
\hline 10 & Catarinense da Ciência Contábil & CRC/SC & B3 & 0 \\
\hline 11 & Contabilidade, Gestão E Governança & UNB & B4 & 0 \\
\hline 12 & Revista de Contabilidade e Controladoria & UFPR & B4 & 0 \\
\hline 13 & Revista Contabilidade e Finanças & FEA/USP & B3 & 0 \\
\hline 14 & Contemporânea de Contabilidade & UFSC & B1 & 1 \\
\hline 15 & Revista Mineira de Contabilidade & CRC/MG & B5 & 0 \\
\hline
\end{tabular}



produção científica. Revista Unemat de Contabilidade, v. 6, n. 12, 2017.

\begin{tabular}{|r|l|c|c|c|}
16 & Revista UNEMAT de Contabilidade & UNEMAT & B4 & 0 \\
\hline 17 & $\begin{array}{l}\text { de Auditoria, Governança e } \\
\text { Contabilidade }\end{array}$ & FUNCAMP & B4 & 0 \\
\hline 18 & Revista de Contabilidade da UFBA & UFBA & B4 & 1 \\
\hline 19 & $\begin{array}{l}\text { de Contabilidade do Mestrado em } \\
\text { Ciências Contábeis }\end{array}$ & UERJ & B5 & 0 \\
\hline 20 & de Contabilidade e Organizações & USP & B1 & 0 \\
\hline 21 & Sociedade, Contabilidade e Gestão & UFRJ & B3 & 0 \\
\hline 22 & $\begin{array}{l}\text { Tecnologias de Administração e } \\
\text { Contabilidade }\end{array}$ & FAT & C & 0 \\
\hline 23 & Revista da Informação Contábil & UFPE & B5 & 0 \\
\hline 24 & Evidenciação Contábil \& Finanças & UFPB & - & 0 \\
\hline 25 & Registro Contábil & UFAL & B3 & 0 \\
\hline 26 & Enfoque: Reflexão Contábil & UEM/PR & B1 & 0 \\
\hline 27 & Revista Borges & FBorges & - & 1 \\
\hline 28 & Congresso ANPCONT & & - & 1 \\
\hline 29 & Congresso Brasileiro de Custos & Amostra da Pesquisa & \\
\hline
\end{tabular}

Fonte: Elaboração própria.

Em consulta realizada às fontes, utilizamos como termo de busca na parte pré-textual dos artigos (título e resumo) a palavra: "depreciação", sendo a escolha da palavra resultado de discussão entre os autores do artigo, com a intenção de separar os artigos científicos que tratassem do tema investigado nesta pesquisa, descartando os que tivessem relação com o ambiente privado.

Com a amostra definida, partimos para a análise de conteúdo avaliando os critérios adotados, como inovação, conhecimento e pesquisa; procedimentos metodológicos; arcabouço estatístico; base de dados referencial; quantidade de pesquisadores envolvidos na construção da pesquisa; aspecto espacial determinando a progressão dos estudos por região; aspecto temporal definindo o período com maior discussão sobre o tema; e aspecto pessoal apontando a vinculação dos autores a sua IES de origem e outros. A lista descritiva dos aspectos explorados consta no Quadro 2 abaixo indicado.

Quadro 2. Aspectos explorados para realização da análise descritiva

\begin{tabular}{|r|l|c|}
\hline $\mathbf{N}^{\mathbf{0}}$ & \multicolumn{1}{|c|}{ Check list } & \multirow{2}{*}{ Aspectos } \\
\cline { 1 - 2 } 1. & Termo de busca "depreciação" nos títulos ou nos resumos. & \multirow{2}{*}{ Pré-textuais } \\
\cline { 1 - 2 } 2. & Quantidade de autores. & \\
\hline 3. & Titulação dos autores. & \\
\hline
\end{tabular}




\begin{tabular}{|r|l|c|} 
& Procedimentos adotados para o desenvolvimento das & \multirow{2}{*}{ Textuais } \\
4. & pesquisas. & \\
\hline 5. & Tipo de abordagem: normativa ou positiva. & \\
\hline 6. & Autores mais citados. & \multirow{2}{*}{ Pós-textuais } \\
\hline 7. & Sugestões dadas para novos estudos. & Espacial \\
\hline 8. & Referências utilizadas (nacional e/ou internacional). & Temporal \\
\hline 9. & Região com mais estudos desenvolvidos na área. & \\
\hline 10. & Período com maior discussão sobre o tema. &
\end{tabular}

Fonte: Adaptado de Moreno et al (2013).

Os dados coletados por intermédio dos procedimentos adotados foram organizados, permitindo a consequente análise dos dados e posterior alcance do resultado.

\section{Análise de resultado}

Realizamos a análise dos resultados partindo inicialmente da evolução temporal da quantidade total de artigos publicados e dos artigos da área, como mostra a Figura 1 abaixo.

Figura 1. Evolução Temporal dos artigos publicados.

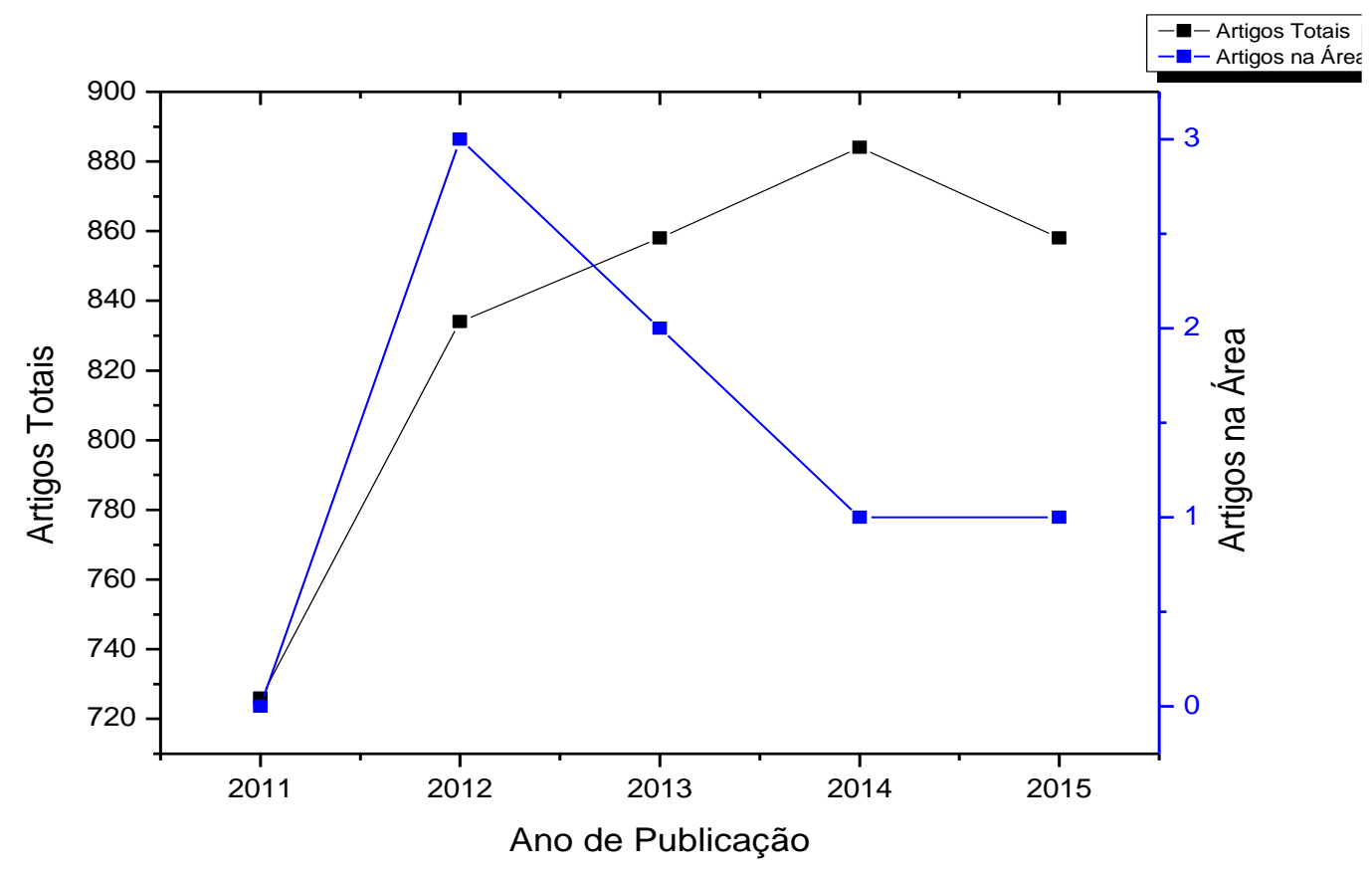

Fonte: Elaboração própria.

É interessante notar que no quinquênio analisado houve apenas sete artigos publicados na área. Podemos perceber também que as variáveis (artigos totais publicados e artigos na área) estão anticorrelacionadas. Isso porque enquanto a quantidade total de artigos vem crescendo, a 
quantidade de artigos na área vem diminuindo, indicando pouco interesse no estudo do tema aqui abordado. Os artigos que possuem qualificação CAPES estão distribuídos nos níveis B1, B3 e B4. Nesse período tiveram um total de duas citações de acordo com o Google Acadêmico, ressaltando o fator de impacto para os artigos mais citados em outras publicações científicas. Vale ainda evidenciar que o período que contemplou um maior número de publicação foi o ano de 2012. Acreditamos que isso tenha ocorrido pela obrigatoriedade da implantação da depreciação no ambiente público, em conformidade com as Normas Brasileiras de Contabilidade Aplicadas ao Setor Público.

Os artigos apresentaram mais de uma autoria como indicado na Tabela 1.

Tabela 1. Quantidade de autores.

\begin{tabular}{|c|c|c|}
\hline Autores & Artigos & \multicolumn{1}{c|}{$\%$} \\
\hline 5 & 1 & $14 \%$ \\
\hline 4 & 4 & $57 \%$ \\
\hline 3 & 1 & $14 \%$ \\
\hline 2 & 1 & $14 \%$ \\
\hline Total & 7 & $100 \%$ \\
\hline
\end{tabular}

Fonte: Elaboração própria.

Como observado na tabela acima se constatou que o número de autor por artigo na maior parte da amostra foi composto por quatro pesquisadores. Além disso, nenhum dos artigos teve apenas uma autoria, ficando clara a importância da troca de experiências entre pesquisadores envolvidos em uma ou mais áreas para a discussão dos problemas investigados no âmbito social.

Também foi feito o levantamento da titulação dos autores na Tabela 2. Os pesquisadores envolvidos totalizam 26 com as titulações apresentadas a seguir.

Tabela 2. Titulação dos autores.

\begin{tabular}{|l|r|r|}
\hline \multicolumn{1}{|c|}{ Titulações } & \multicolumn{1}{c|}{ Autores } & \multicolumn{1}{c|}{$\%$} \\
\hline Graduado & 5 & $19 \%$ \\
\hline Especialista & 2 & $8 \%$ \\
\hline Mestrado & 12 & $46 \%$ \\
\hline Doutorado & 7 & $27 \%$ \\
\hline Total & 26 & $100 \%$ \\
\hline
\end{tabular}

Fonte: Elaboração própria.

Observamos que $46 \%$ dos autores tem titulação de mestre. Dessa forma, é perceptível o envolvimento de pós-graduados com participação efetiva em publicação de artigos totalizando neste estudo $81 \%$. Isso tem sido bastante comum, pois a pós-graduação oferece melhor 
preparação, interação e envolvimento em pesquisas científicas de bom nível, investigando problemas de caráter social e outros.

No que diz respeito aos objetivos que foram traçados nos artigos científicos e que mostram a intenção dos autores em desenvolver a pesquisa, percebemos que tais objetivos estão correlacionados, pois todos procuram mostrar o comportamento da administração pública frente a obrigatoriedade do registro da depreciação do patrimônio público, como exposto na Tabela 3.

Tabela 3. Objetivos traçados.

\begin{tabular}{|l|c|c|}
\hline \multicolumn{1}{|c|}{ Objetivos } & Artigos & \% \\
\hline $\begin{array}{l}\text { Verificar o reconhecimento e a evidenciação nos demonstrativos } \\
\text { contábeis. }\end{array}$ & 2 & $29 \%$ \\
\hline Investigar as dificuldades na implantação das normas vigentes. & 1 & $14 \%$ \\
\hline Identificar os impactos nos índices econômicos e financeiros. & 1 & $14 \%$ \\
\hline Demonstrar os procedimentos e normatização após harmonização. & 2 & $29 \%$ \\
\hline $\begin{array}{l}\text { Investigar o grau de aderência dos órgãos à contabilização e ao } \\
\text { disclosure. }\end{array}$ & 1 & $14 \%$ \\
\hline Total & 7 & $100 \%$ \\
\hline
\end{tabular}

Fonte: Elaboração própria.

Quanto aos procedimentos adotados na pesquisa, notamos a maior classificação para Estudo de Caso, como consta na Tabela 4.

Tabela 4. Procedimentos adotados.

\begin{tabular}{|l|c|r|}
\hline \multicolumn{1}{|c|}{ Procedimentos } & Artigos & \multicolumn{1}{c|}{$\%$} \\
\hline $\begin{array}{l}\text { Qualitativa e } \\
\text { Quantitativa }\end{array}$ & 2 & $28,5 \%$ \\
\hline Qualitativa & 3 & $43 \%$ \\
\hline Quantitativa & 2 & $28,5 \%$ \\
\hline Total & 7 & $100 \%$ \\
\hline \multicolumn{2}{|l}{ Fonte: Elaboração própria. }
\end{tabular}

O estudo de caso tem sido amplamente utilizado em pesquisas relacionadas às Ciências Sociais. De acordo com Yin (2015) esse procedimento requer um aprofundamento do estudo exigindo a observação direta do pesquisador, se enquadrando como pesquisa de característica qualitativa.

No que se refere à abordagem escolhida para o desenvolvimento dos artigos $71 \%$ dos artigos que fazem parte da amostra fizeram uso da abordagem normativa, conforme apresentado na Tabela 5.

Tabela 5. Abordagem Normativa ou Positiva.

\begin{tabular}{|c|c|c|}
\hline Abordagens & Artigos & $\%$ \\
\hline
\end{tabular}




\begin{tabular}{|l|r|r|} 
Normativa & 5 & $71 \%$ \\
\hline Positiva & 2 & $29 \%$ \\
\hline Total & 7 & $100 \%$ \\
\hline
\end{tabular}

Fonte: Elaboração própria.

De acordo com Spessatto e Bezerra (2008) enquanto a abordagem normativa se caracteriza pela exploração das práticas contábeis em comparação com as normas sem o uso de testes que tornem válido o resultado da pesquisa, a abordagem positiva se caracteriza pelo acompanhamento dos fatos que ocorrem na prática, testando hipóteses com auxílio de métodos estatísticos para comprová-los.

Quanto aos autores mais citados nos artigos percebemos que o livro mais consultado foi o de Teoria da Contabilidade, tratando do imobilizado e consequentemente da depreciação incidente sobre ele. Além disso, tivemos também outros materiais mais consultados que envolveram Contabilidade Pública e Governamental, enfatizando a depreciação no ambiente público, Evidenciação Contábil, reconhecendo a depreciação nos demonstrativos contábeis e Metodologias para projetos de pesquisa e trabalhos monográficos, ressaltando mecanismos para a elaboração de trabalhos científicos. A Tabela 6 a seguir apresenta por posição os autores mais consultados e a quantidade de artigos em que seus nomes foram citados.

Tabela 6. Autores mais consultados e área de estudo.

\begin{tabular}{|c|c|c|c|}
\hline $\mathbf{N}^{\circ}$ & Autores & Conteúdo & Artigos \\
\hline $1^{\circ}$ & $\begin{array}{c}\text { HENDRIKSEN e } \\
\text { VAN BREDA }\end{array}$ & $\begin{array}{c}\text { Teoria de } \\
\text { Contabilidade }\end{array}$ & 5 \\
\hline \multirow{4}{*}{$2^{\circ}$} & BEUREN, I. M. & $\begin{array}{c}\text { Trabalhos } \\
\text { Monográficos }\end{array}$ & 4 \\
\cline { 2 - 4 } & SILVA, L. M. & $\begin{array}{c}\text { Contabilidade } \\
\text { Governamental }\end{array}$ & 4 \\
\hline \multirow{4}{*}{$3^{\circ}$} & DANTAS, C. B. & $\begin{array}{c}\text { Depreciação no } \\
\text { Serviço Público }\end{array}$ & 3 \\
\cline { 2 - 4 } & GIL, A. C. & Projetos de Pesquisa & 3 \\
\cline { 2 - 5 } & IUDICIBUS, S. de & $\begin{array}{c}\text { Teoria da } \\
\text { Contabilidade }\end{array}$ & 3 \\
\cline { 2 - 5 } & $\begin{array}{c}\text { RICHARDSON, R. } \\
\text { J. }\end{array}$ & $\begin{array}{c}\text { Pesquisa Social: } \\
\text { Métodos e Técnicas }\end{array}$ & 3 \\
\hline \multirow{4}{*}{$4^{\circ}$} & $\begin{array}{c}\text { NASCIMENTO, L. } \\
\text { S. }\end{array}$ & $\begin{array}{c}\text { Evidenciação } \\
\text { Contábil }\end{array}$ & 2 \\
\cline { 2 - 5 } & SLOMSKI, V. & Contabilidade Pública & 2 \\
\cline { 2 - 5 } & SHARF, L. & Depreciação & 2 \\
\cline { 2 - 5 } & VIANA, C. C. & $\begin{array}{c}\text { Depreciação no Setor } \\
\text { Público }\end{array}$ & 2 \\
\hline Total & & & \\
\hline
\end{tabular}

Fonte: Elaboração própria. 

produção científica. Revista Unemat de Contabilidade, v. 6, n. 12, 2017.

Relacionamos a seguir (Tabela 7) as sugestões fornecidas nos artigos para a elaboração de novas pesquisas explorando a depreciação no ambiente público após a convergência das normas aos padrões internacionais.

Tabela 7. Sugestões fornecidas para elaboração de novas pesquisas

\begin{tabular}{|l|c|c|}
\hline \multicolumn{1}{|c|}{ Sugestões } & Artigos & \% \\
\hline Efeitos da depreciação nas Demonstrações Contábeis. & 1 & $14 \%$ \\
\hline Causas do descumprimento da reavaliação e do impairment. & 2 & $29 \%$ \\
\hline Impactos gerados com a aplicação das novas regras. & 3 & $43 \%$ \\
\hline $\begin{array}{l}\text { Principais obstáculos para divulgação da depreciação após a } \\
\text { harmonização. }\end{array}$ & 1 & $14 \%$ \\
\hline Total & 7 & $100 \%$ \\
\hline
\end{tabular}

Fonte: Elaboração própria.

Os temas mais sugeridos dizem respeito aos impactos gerados com a aplicação dessa nova sistemática e as causas do descumprimento da reavaliação e do teste de impairment, possivelmente presentes no ambiente público.

As referências utilizadas para o desenvolvimento dos artigos envolveram em sua maior parte referências nacionais e internacionais permitindo o aprimoramento de conteúdo, por investigar outros povos com características sociais (cultura, tradição e religião), econômicas (oferta e demanda) e políticas (órgãos governamentais, grupos de pressão e outros) diversificadas.

A região com mais artigos publicados foi a Região Sul com pesquisadores vinculados à Universidade Federal de Santa Catarina e Universidade Regional de Blumenau, conforme demonstrado na Tabela 8.

Tabela 8. Artigos por região.

\begin{tabular}{|c|c|c|}
\hline Regiões & Artigos & Instituições \\
\hline Norte & 1 & UFAM \\
\hline \multirow{2}{*}{ Sul } & 1 & FURB \\
\cline { 2 - 3 } & 2 & UFSC \\
\hline Centro-Oeste & 0 & - \\
\hline \multirow{2}{*}{ Sudeste } & 2 & UFES \\
\cline { 2 - 3 } & & UERJ \\
\hline \multirow{2}{*}{ Nordeste } & 1 & UFPB \\
\cline { 2 - 3 } & 7 & UFRN \\
\hline Total & 7 & 6 \\
\hline
\end{tabular}

Fonte: Elaboração Própria. 
Dessa forma as pesquisas relacionadas à depreciação no ambiente público, com obrigatoriedade a partir do exercício de 2012, foram exploradas nas regiões destacadas na Figura 2 com maior concentração na Região Sul.

Figura 2. Regiões com maior número de publicação - Mapa do Brasil (político).

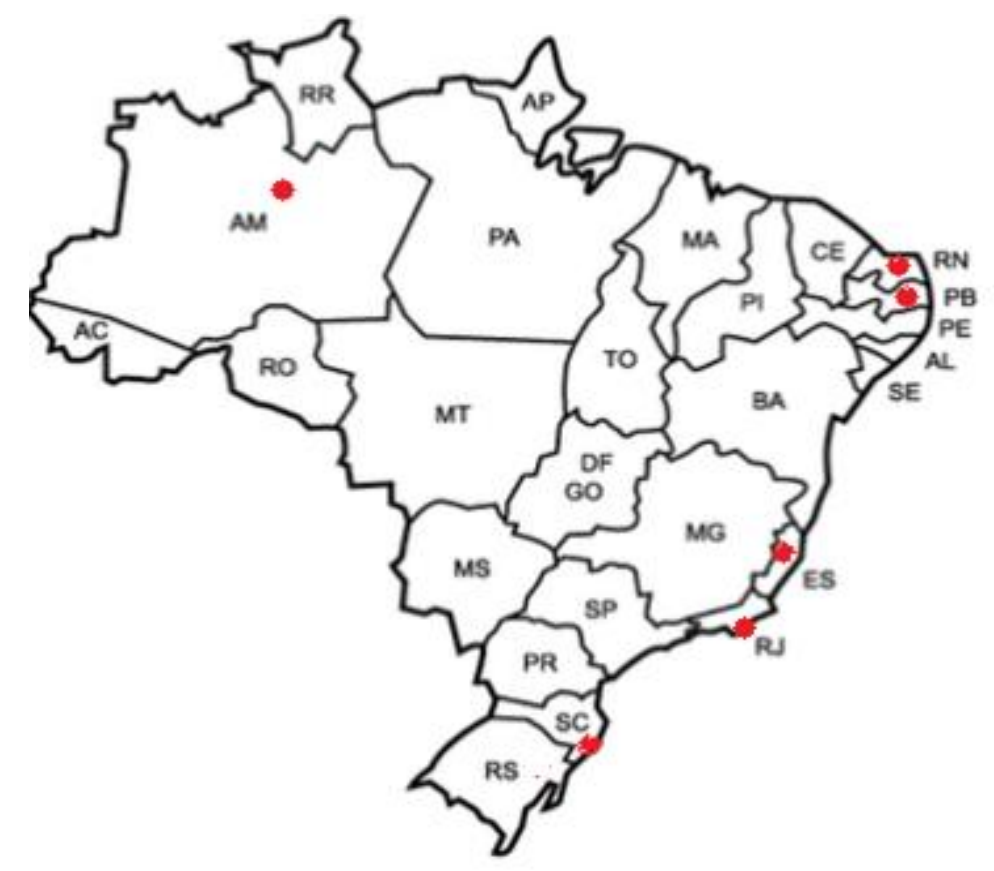

Fonte: Dados da pesquisa. Atlas Escolar.

Assim, constatamos uma ínfima contribuição da pesquisa científica, para a formação acadêmica e profissional dos atuantes na área de Ciências Contábeis ou áreas correlatas, no tocante à depreciação no ambiente público.

\section{CONSIDERAÇÕES FINAIS}

Este estudo teve o propósito de investigar como ocorreu a progressão da pesquisa científica sobre depreciação no âmbito governamental, impulsionada pela harmonização das Normas Brasileiras de Contabilidade Aplicadas ao Setor Público aos padrões internacionais, com reflexo na adaptação dos órgãos a esse novo procedimento, melhorando o controle e a transparência do patrimônio na esfera pública.

O universo da pesquisa foi formado por 24 revistas e 2 eventos da área contábil. $O$ período de análise considerou as publicações de 2011 a 2015. Os artigos selecionados para análise foram aqueles que tinham a expressão "depreciação" no título ou resumo, havendo a 
rejeição para os artigos que estavam associados ao ambiente privado. Com isso, obtivemos a amostra composta por 7 artigos científicos.

No aspecto quantitativo, pôde-se perceber que as variáveis (artigos totais publicados e artigos na área) estão anticorrelacionadas. Isso porque enquanto a quantidade total de artigos vem crescendo, a quantidade de artigos na área vem diminuindo, indicando pouco interesse no estudo do tema aqui abordado. Os artigos que possuem qualificação CAPES foram distribuídos nos níveis B1, B3 e B4. Nesse período tiveram um total de 2 citações de acordo com o Google Acadêmico, o que garante um fator de impacto para os artigos mais citados em outras publicações científicas. Vale ainda evidenciar que o período que contemplou um maior número de publicação foi o ano de 2012. Acreditamos que isso tenha ocorrido pela obrigatoriedade da implantação da depreciação no ambiente público, em conformidade com as Normas Brasileiras de Contabilidade Aplicadas ao Setor Público.

Diante do que foi exposto, concluímos que o nível de progressão da pesquisa científica foi muito baixo, por conta da reduzida contribuição dos pesquisadores para com a temática relacionada ao ambiente público sobre depreciação. Este estudo se concentrou em revistas e eventos brasileiros, determinando assim a limitação da pesquisa. Indicamos a título de sugestão outras pesquisas envolvendo outros países, apontando os procedimentos adotados, realizando comparativos e descrevendo como ocorre o processo de depreciação no ambiente público em outras regiões do globo.

\section{REFERÊNCIAS:}

ATLAS ESCOLAR IBGE. Mapa do Brasil. Disponível em: http://atlasescolar.ibge.gov.br/mapas-atlas Acesso em: 20jun2016.

BEZERRA FILHO, João Eudes. Contabilidade aplicada ao setor público: abordagem simples e objetiva. São Paulo: Atlas, 2014. Encontro de Administração Pública e Governo, Salvador/BA, 18 a 20 de novembro de 2012. Disponível em:

http://www.anpad.org.br/diversos/trabalhos/EnAPG/enapg_2012/2012_EnAPG397.pdf Acesso em: 23 jun2016.

BORGHETTI, Jonas; BORGHETTI, Júlio César; STEIN, Felipe André; FROSI, Miriam; RODRIGUES, Elisângela Batista Maciel. Impactos do Reconhecimento da Depreciação no Setor Público para o Patrimônio dos Estados Brasileiros. Encontro de Administração Pública e Governo - EnAPG, Salvador - nov/2012. Disponível em: http://www.anpad.org.br/diversos/trabalhos/EnAPG/enapg_2012/2012_EnAPG397.pdf Acesso em: 2 jun2016.

BRASIL. Lei n ${ }^{\circ} 10.406$, de 10 de janeiro de 2002. Institui o Código Civil. Disponível em: http://www.planalto.gov.br/ccivil_03/leis/2002/L10406.htm Acesso em: 22Ago2016.

CAFÉ, Lígia; BRÄSCHER, Marisa. Organização da informação e bibliometria. Revista Eletrônica Biblioteconomia. CI. Inf., Florianópolis, n. esp., $1^{\circ}$ semestre, 2008. Disponível em: 
MORENO, G. C. DE L.; MIRANDA, L. C.; SILVA NETO, J. M. DA. Depreciação no setor público: o déficit da produção científica. Revista Unemat de Contabilidade, v. 6, n. 12, 2017.

https://periodicos.ufsc.br/index.php/eb/article/viewFile/1518-2924.2008v13nesp1p54/1032 Acesso em: 31 mar2016.

CARVALHO, R. de M. F.; LIMA, D. V. de; FERREIRA, L. O. G. Processo de Reconhecimento e Mensuração do Ativo Imobilizado no Setor Público face aos padrões contábeis internacionais: Um estudo de caso na ANATEL Revista Universo Contábil, Blumenau, v 8, n 3, p. 62 - 81, jul/set, 2012. Disponível em: http://proxy.furb.br/ojs/index.php/universocontabil/article/view/2652 Acesso em: 5 ago2017.

DALFOVO, Michael Samir; LANA, Rogério Adilson; SILVEIRA, Amélia. Métodos quantitativos e qualitativos: um resgate teórico. Revista Interdisciplinar Científica Aplicada, Blumenau, v. 2, n, 4, p. 01-13, Sem II, 2008. Disponível em:

http://www.unisc.br/portal/upload/com_arquivo/metodos_quantitativos_e_qualitativos_um_resgate_te orico.pdf Acesso em: 4abr2016.

GRACILIANO, Erivelton Araújo; FIALHO, Wilton Clarimar Dutra. Registro da Depreciação na Contabilidade Pública: uma contribuição para o disclosure de gestão. Revista Pensar Contábil, RJ, v. 15, n. 56, p. 14-21, jan/abr 2013. Disponível em: http://www.atena.org.br/revista/ojs-2.2.308/index.php/pensarcontabil/article/view/1540 Acesso em: 31mar2016.

HARZER, Jorge Harry; SOUZA, Alceu. O impacto da depreciação na gestão dos custos de uma empresa prestadora de serviço público de abastecimento de água frente ao pronunciamento técnico 27 do Comitê de Pronunciamentos Contábeis. Revista Perspectivas Contemporâneas, v. 9, n. 2, p. 7595, jul/dez, 2014. Disponível em:

http://revista.grupointegrado.br/revista/index.php/perspectivascontemporaneas/article/view/1378/617 Acesso em: 31mar2016.

HAYASHI, Maria Cristina Piumbato Innocentini. Sociologia da ciência, bibliometria e cientometria: Contribuições para a análise da produção científica. Anais eletrônico - IV EPISTED - Seminário de Epistemologia e Teoria da Educação, UNICAMP, dez/2012. Disponível em: https://www.fe.unicamp.br/eventos/ged/episted/EPISTED/paper/viewFile/102/61 Acesso em: $31 \mathrm{mar} 2016$.

MCASP. Manual de Contabilidade Aplicada ao Setor Público. Disponível em: http://www.tesouro.fazenda.gov.br/documents/10180/456785/CPU_MCASP+6\%C2\%AA\%20edi\%C3 \%A7\%C3\%A3o_Republ2/fa1ee713-2fd3-4f51-8182-a542ce123773 Acesso em: 02abr2016.

MIRANDA, Guilherme Cardoso; LIMA, Diana Vaz de; FERREIRA, Lucas Oliveira Gomes. Modelo de Processo de Depreciação de Bens Móveis no Setor Público: um estudo no Tribunal Regional do Trabalho da $10^{\text {a }}$ Região. XXXIV Encontro ANPAD, Rio de Janeiro - 25 a 29 de setembro de 2010. Disponível em: http://www.anpad.org.br/admin/pdf/apb936.pdf Acesso em: 31mar2016.

MORENO, Gleice Carvalho de Lima; LOPES, Jorge Expedito; PEDERNEIRAS, Marcleide Maria Macedo; RIBEIRO FILHO, José Francisco. Uma análise bibliométrica da pesquisa científica em governança corporativa: Uma investigação nos trabalhos apresentados nos Congressos da ANPCONT e da USP 2007-2010. Revista Estudo \& Debate, Lajeado, v. 20, n. 2, p. 75-95, 2013. Disponível em: http://www.univates.br/revistas/index.php/estudoedebate/article/view/670 Acesso em: 3maio2016.

NBC T 16.9. Normas Brasileiras de Contabilidade Aplicadas ao Setor Público - Depreciação, Amortização e Exaustão. Disponível em: http://www.cfc.org.br/uparq/NBCT16 9.pdf Acesso em: 12 jun 2016.

ROZA, Mariana Costa da; MACHADO, Débora Gomes; QUINTANA, Alexandre Costa. Análise bibliométrica da produção científica sobre contabilidade pública no Encontro de Administração Pública e Governança (ENAPG) e na Revista de Administração Pública (RAP), no período 20042009. Revista ConTexto, Porto Alegre, v. 11, n. 20, p. 59-72, $2^{\circ}$ semestre de 2011. Disponível em: http://seer.ufrgs.br/index.php/ConTexto/article/view/19984/pdf_1 Acesso em: 5abr2016. 
SILVA, Mauricio Corrêa da; COSTA, Giovanni Baptista; BOENTE, Diego Rodrigues; BATISTA, Edmilson Monteiro. Depreciação no Setor Público: análise de procedimentos em uma Unidade Gestora. Boletim de Orçamento e Finanças - Governet, nº 73, p. 418-432, maio/2011. Disponível em: https://sigaa.ufrn.br/sigaa/verProducao?idProducao=714336\&key=9a9ed0247194422de60238773 28db732. Acesso em: 02abr2016.

SILVA, Júlio César da; SILVA, Alini; PLETSCH, Caroline Sulzbach; ROSA, Fabricia Silva. O Impacto da Depreciação nos Índices Econômicos e Financeiros de uma Organização Pública pela aplicação da Ipsas 17. Pensar Contábil, Rio de Janeiro, v. 16, n. 60, p. 32 - 40, maio/ago. 2014. Disponível em: http://www.atena.org.br/revista/ojs-2.2.306/index.php/pensarcontabil/article/viewFile/2191/1928 Acesso em: 23jun2016.

SPESSATTO, Giseli; BEZERRA, Francisco A. Utilização das abordagens positiva e normativas nas pesquisas em contabilidade. XV Congresso Brasileiro de Custos - Cutitiba/PR, Brasil, 12 a 14 de novembro de 2008. Disponível em:

https://anaiscbc.emnuvens.com.br/anais/article/download/1193/1193 Acesso em: 15jun2016.

TEDROS, Leonardo de Sá; CAITANO, Regeslane Candida; GAMA, Janyluce Rezende; CALIMAN, Douglas Roriz. Depreciação no setor público: Um estudo em uma instituição pública de ensino superior. IX Congresso ANPCONT, Curtiba/PR, 2015. Disponível em: http://congressos.anpcont.org.br/ix/anais/files/2015-05/cpt058.pdf Acesso em: 22ago2016.

TESOURO NACIONAL. Normas Internacionais de Contabilidade para o Setor Público - NICSP e o Modelo Contábil adotado no Brasil. Abril 2007. Disponível em:

http://socialiris.org/imagem/boletim/arq4aa01df4ae39b.pdf Acesso em: 02abr2016.

VIANA, Clilson Castro; TAMER, Carla Macedo Velloso dos Santos; SOARES, Luiz Augusto de Carvalho Francisco; LIMA, Mariomar de Sales. Implantação da depreciação no setor público e procedimentos contábeis: um estudo em uma instituição pública de ensino superior. Revista Contemporânea de Contabilidade, v. 10, n. 20, p. 113-138, UFSC, Florianópolis, maio/agos, 2013. Disponível em: https://periodicos.ufsc.br/index.php/contabilidade/article/download/21758069.2013v10n20p113/25195 Acesso em: 03abr2016.

YIN, Robert K. Estudo de caso: Planejamento e Métodos. 5ª Ed. São Paulo: Saraiva, 2015. 